Review

\title{
Barbituric Acid Utility in Multi-Component Reactions
}

\author{
Raafat M. Shaker and Esam A. Ishak \\ Chemistry Department, College of Science, Al-Jouf University, Sakaka, Kingdom of Saudi Arabia \\ Reprint requests to Prof. Dr. Raafat M. Shaker. E-mail: rmshaker@yahoo.com
}

Z. Naturforsch. 2011, 66b, 1189 - 1201; received August 20, 2011

This review describes the multi-component reactions of barbituric acid derivatives as building blocks for the synthesis of heterocyclic compounds with pharmacological interest.

Key words: Barbituric Acid Derivatives, Multi-Component Reactions, Pharmacological Activities

\section{Introduction}

A large number of barbituric acid derivatives have attracted the attention of the pharmaceutical community for more than a century due to their various biological effects [1-4]. They are known to possess a wide range of activities, such as inhibiting collagenase-3 (MMP-3) [5], matrix metalloproteinases [6], recombinant cytochrome P450 enzymes [7], methionine aminopeptidase-1 (MetAP-1) [8], hypnotic [9-13], sedative $[14,15]$, antibacterial $[8,16-21]$, anticonvulsant (antiepileptic) [22-24], anti-invasive [25], antitumor [25,26], antiangiogenic [25], anticancer [2730], immuno-modulating [30], herbicides [12], fungicides [31], antiviral [32], antioxidant [33,34], and HIV-1 integrase inhibitors [35,36]. Also, barbiturates are a class of drugs that are utilized as anesthetics and sleeping agents and are used for the treatment of anxiety, epilepsy and other psychiatric disorders, and possess effects on the motor and sensory functions [3743]. Structure-activity relationship shows that heterocyclic/substituted aryl moieties at the 5-position of the barbituric [44-46] and thiobarbituric [47,48] nucleus remarkably increase the biological activity. For example, Phenobarbital (5-ethyl-5-phenylbarbituric acid) is the drug used most commonly for convulsive disorders and is the drug of choice for infants and young children [49]. Moreover, spiro barbiturates are a class of compounds with interesting pharmacological and physiological activity [50-54].

Multi-component reactions (MCRs) play an increasingly important role in organic and medicinal chemistry because of their convergence, productivity, ease of execution, excellent yields, and broad applications in combinational chemistry [55-58].
However, no comprehensive analysis of multicomponent reactions with barbituric acids has been made till date, which gave the reason for writing the present review covering the literature from the late 1964 until 2011. Our survey focuses only on MCRs involving at least three different substrates, with no discussion being made of transformations dealing with the two-component reactions of barbituric acids with another substrate. Generally, multi-component treatments of barbituric acids can be divided according to the sections that follow.

\section{MCRs based on the Mannich reaction}

The Mannich reaction is a powerful synthetic method for the preparation of $\beta$-amino carbonyl compounds, an important class of building blocks of pharmaceutically relevant compounds $[59,60]$. In addition it has been reported [61] that insertion of an (arylamino)methyl moiety at position 5 of thiobarbituric acid or barbituric acid enhances the antidepressant activities of the resultant compounds. The aminomethyl group is usually introduced in the 1- and/or 3-position of the barbituric ring, and in some cases at the 5position. The $\mathrm{NH}$ groups of barbituric acids easily take part in Mannich reactions [62,63]. 5-Ethylbarbituric acid yielded the $N, C$-bis(piperidinomethyl) derivative 1 during aminomethylation with formaldehyde and piperidine [64].

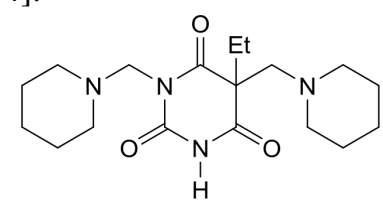

1

(C) 2011 Verlag der Zeitschrift für Naturforschung, Tübingen · http://znaturforsch.com 
The second NH group in $2\left(\mathrm{R}^{1}=\mathrm{Me}, \mathrm{Et} ; \mathrm{R}^{2}=\mathrm{Ph}\right.$, cyclohexenyl) did not undergo further aminomethylation. The reaction led only to the $N$-aminomethyl product $3\left(\mathrm{R}^{1}=\mathrm{Me}, \mathrm{Et} ; \mathrm{R}^{2}=\mathrm{Ph}\right.$, cyclohexenyl). This was explained by the formation of the lactim form, which renders the other hydrogen atom inaccessible to a second condensation reaction owing to the stabilization of the lactim moiety by an intermolecular hydrogen bond [65].

On the other hand, Danielsson and Dolby [66] showed that aminomethylation in the 1- and 3positions was possible in both 5,5-diethyl- and 5-ethyl5-phenylbarbituric acids when formaldehyde and morpholine were used as the reagents.<smiles>[R]C1([R])C(=O)NC(=O)NC1=O</smiles>

2

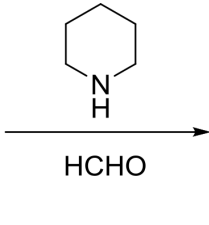<smiles>[R]C1([R])C(=O)NC(O)=NCN1CC1CCCCC1</smiles>

3
Furthermore, Werner and Fritzsche [67] found that 1-aminomethylated 5,5-disubstituted barbituric acids 4 have nonchelated $\mathrm{NH}$ groups, and that a second aminomethylation is possible at the $\mathrm{N}-3$ atom.<smiles>[R]CN1C(=O)NC(=O)C(CC)(C2=CCCCC2)C1=O</smiles>

4

Also, there are known cases of the Mannich reaction at the 5-position. Thus, Sladowska [68] obtained the series of 5-alkyl-5-aminomethyl-1,3-dicyclohexylbarbituric acids $\left(\mathbf{5}, \mathrm{R}^{1}=\mathrm{Et}\right.$, allyl; $\mathrm{R}^{2}=1$-piperidinyl, 1 - pyrrolidinyl, 1-morpholinyl) from 5-alkyl-1,3-dicyclohexyl-barbituric acids.<smiles>[R]CC1([R])C(=O)N(C2CCCCC2)C(=O)N(C2CCCCC2)C1=O</smiles>

5

$N, N^{\prime}$-Bis(5,5-diethyl-1-barbiturylmethyl)piperazine (6) has been synthesized by condensation of 5,5-diethylbarbituric acid with formaldehyde and piperazine following a Mannich procedure [69].<smiles>CCC1(CC)C(=O)NC(=O)N(CN2CCN(CN3C(=O)NC(=O)C(CC)(CC)C3=O)CC2)C1=O</smiles>

The 2-thiobarbituric acids enter into Mannich reactions with formaldehyde, piperidine [70] or morpholine [70], and with anilines [71,72] giving rise to the corresponding 5-aminomethyl derivatives 7-9, respectively.<smiles>O=C1NC(=S)NC(=O)C1CN1CCCCC1</smiles><smiles>O=C1NC(=S)NC(=O)C1CN1CCOCC1</smiles><smiles>O=C1NC(=S)NC(=O)C1CNc1ccccc1</smiles>

Kidwai et al. [73], have described the one-pot synthesis of substituted barbituric and thiobarbituric acids $\mathbf{1 3 a}-\mathbf{h}$ using montmorillonite clay in dry media under microwave irradiation (MWI). Reactions between 10a, $\mathbf{b}, \mathbf{1 1} \mathbf{a}, \mathbf{b}$, and 12a $(X=O), \mathbf{b}(X=S)$ under conven-

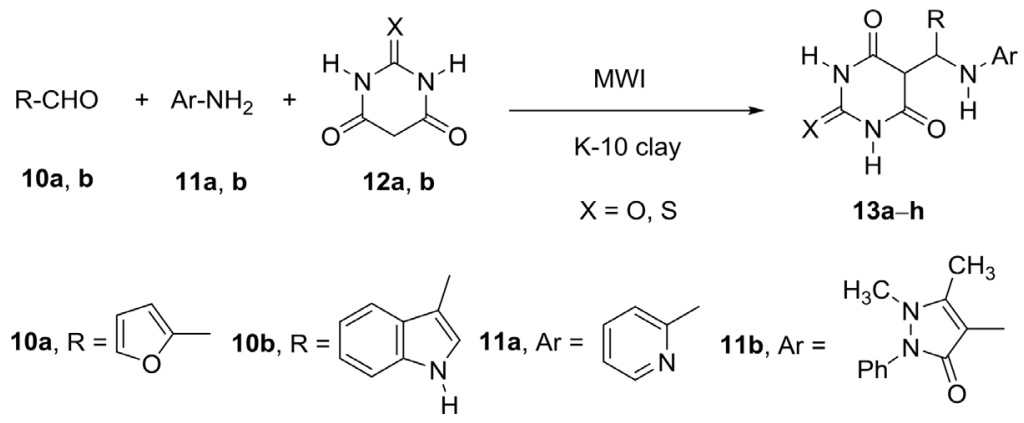


<smiles></smiles>

14<smiles></smiles>

15 tional heating were completed in 10-12 hours with moderate yield, whereas the same reactions under MWI gave excellent yields within few minutes of irradiation. All the compounds synthesized were found to possess good antifungal activity [73].
The reactions of barbituric acids 12a, b with formaldehyde and piperidine or morpholine gave the corresponding Mannich bases 14 and 15 [74].

An efficient, unusual Mannich-type reaction of tertiary aromatic amines, formaldehyde and $N, N^{\prime}$-dimethylbarbituric acid (1,3-dimethylbarbituric acid, 12c) is described in aqueous micelles catalyzed by boric acid to afford the 5-dialkylaminoaryl-1,3-dimethylpyrimidine-2,4,6-triones $\mathbf{1 6}$ and 17 [75]. The reaction is highly regioselective, and exclusively parafunctionalized products are formed in high yields [75].

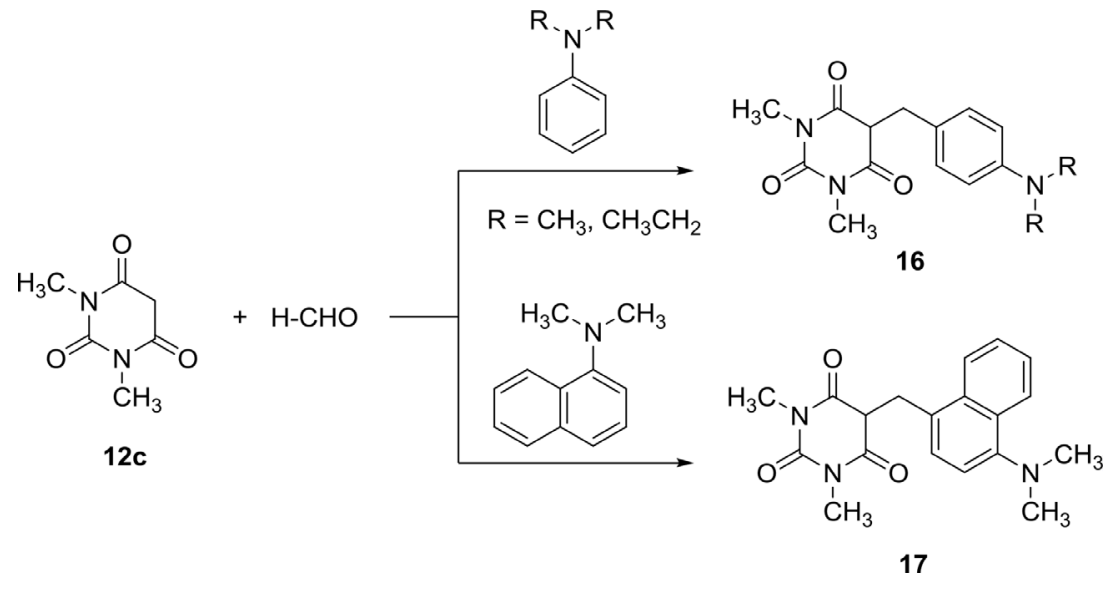<smiles>[X]c1ccc2nc(C)n(NCC(=O)NNNC(N)=S)c(=O)c2c1</smiles>

12a, b 18<smiles>[X]C1=NC(=O)C(CNC(=S)NNC(=O)CNn2c(C)nc3ccc([Y])cc3c2=O)C(=O)N1</smiles>

19, $X=O, S, Y=H, B r, I$

Anticonvulsant activities of (halosubstituted quinazolinonyl-thiosemicarbazido)-barbituric and -thiobarbituric acids 19, which were prepared from the reaction of barbituric acids $\mathbf{1 2 a}(X=O), \mathbf{b}(X=S)$ with formaldehyde and thiosemicarbazides $\mathbf{1 8}$, have been reported [23]. From the results of studies of the biological activities it was concluded that the presence of the bromo group at the 6-position of the quinazolinone nucleus was found to increase the anticonvulsant activity. Furthermore, incorporation of 2-thiobarbituric acid in 18 was found to increase the potency of these compounds and resulted in the formation of $\mathbf{1 9}$ with high anticonvulsant activity [23].

The 1,3,4-thiadiazoles 20 were combined with barbituric and thiobarbituric acid via Mannich reaction to yield $\left(1^{\prime}, 3^{\prime}, 4^{\prime}\right.$-thiadiazol-2'-yl)-barbituric and thiobarbituric acids 21 which showed an activity (90\%) more<smiles>[X]c1ccc2nc(C)n(NCc3nnc(N)s3)c(=O)c2c1</smiles>
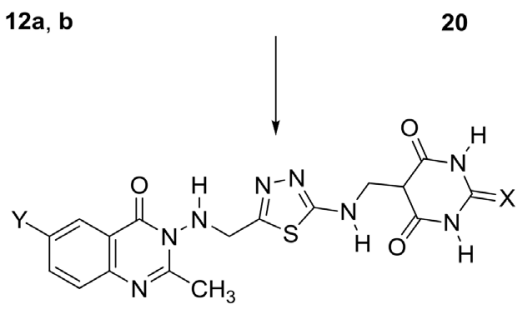

21, $\mathrm{X}=\mathrm{O}, \mathrm{S}, \mathrm{Y}=\mathrm{H}, \mathrm{Br}, \mathrm{I}$ 
potent than the standard drug [23]. These compounds showed anticonvulsant activity. Furthermore, incorporation of thiobarbituric acid in $\mathbf{2 0}$ was found to increase the potency of these compounds and resulted in the formation of $\mathbf{2 1}$ with high anticonvulsant activity [23].

The reaction of $1 N, N^{\prime}$-dimethylbarbituric acid (12c) with formaldehyde and 2,5-dimethylpiperazine gave the bis Mannich base 22 [74].<smiles>CC1CN(Cc2c(O)n(C)c(=O)n(C)c2=O)CC(C)N1Cc1c(O)n(C)c(=O)n(C)c1=O</smiles>

22

\section{MCRs based on the Knoevenagel Reaction}

The Knoevenagel reaction consists of the condensation of aldehydes or ketones with active methylene compounds usually performed in a weakly basic medium [76]. It is well-known that nitrogen-contain- ing compounds such as pyrimidines and imidazole derivatives are of widespread interest in pharmacology. Thus, a catalyst-free three-component transformation combining both heterocycles was developed involving $N, N^{\prime}$-dimethylbarbituric acid (12c), arylglyoxals (23), and dimethylurea (24) in methanol heated at reflux to furnish imidazolylpyrimidinone 25 [77]. Results of mechanistic investigations were in accordance with a Knoevenagel-initiated process followed by an aza-Michael addition of a urea moiety and cyclodehydration.

One-pot three-component condensation reactions of isocyanides 26, aldehydes 27 and $N, N^{\prime}$-dimethylbarbituric acid (12c) afforded furopyrimidinones 28 [78].

The 5,5'-(1,4-phenylene)di(furo[2,3- $d]$ pyrimidine2,4(1H,3H)-dione) derivatives 30 were obtained from the reaction of isocyanides $\mathbf{2 6}$, terephthalaldehyde (29) and $N, N^{\prime}$-dimethylbarbituric acid (12c) via efficient one-pot three-component condensation reactions [79].<smiles>CNC(=O)N(C)CC(=O)O</smiles>

12c

23

24

25<smiles></smiles>

$12 \mathrm{c}$

28<smiles></smiles> 


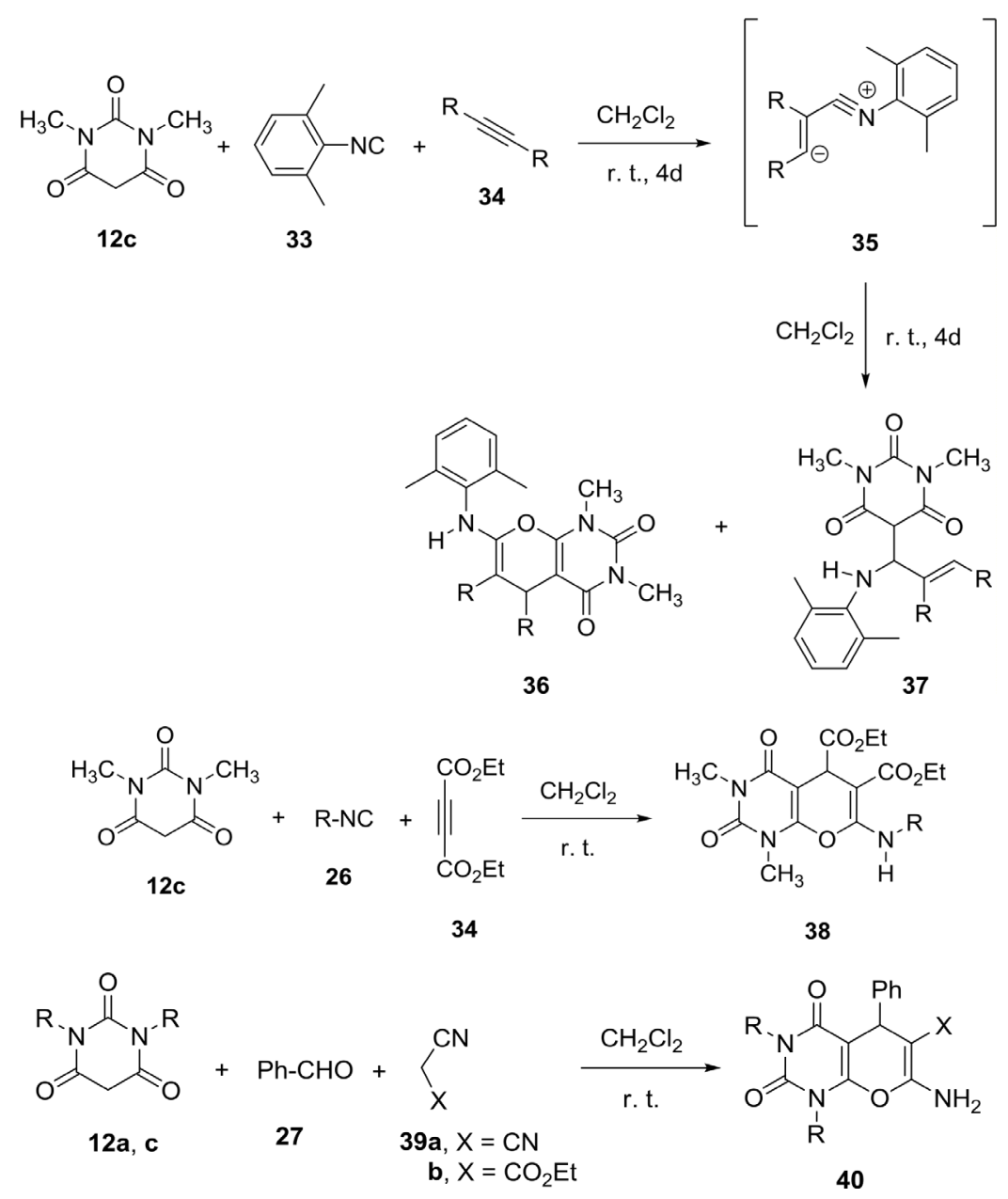

The reaction of isocyanides $\mathbf{2 6}$ and ethynyl phenyl ketone 31 with $N, N^{\prime}$-dimethylbarbituric acid (12c) yielded the pyrano[2,3- $d]$ pyrimidine-5-carboxamides 32 in good yields after 4 days at r. t. [80].

The production of the reactive intermediate 35 in the reaction between 2,6-dimethylphenyl isocyanide (33) and acetylenes 34 was described by Yavari et al. [81], where the reactive intermediate $\mathbf{3 5}$ was trapped by $N, N^{\prime}$-dimethylbarbituric acid (12c) to yield the isomeric products $\mathbf{3 6}$ and $\mathbf{3 7}$ in a nearly $1: 1$ ratio and an overall yield of $85 \%$.

The isocyanides 26, dimethyl acetylenedicarboxylate $\left(34, \mathrm{R}=\mathrm{CO}_{2} \mathrm{Et}\right)$ and $N, N^{\prime}$-dimethylbarbituric acid (12c) undergo smooth 1:1:1 addition reactions in dichloromethane at r. t. to produce the $4 H$-pyrano[3,2$d$ ]pyrimidines 38 [82].

Microwave-assisted three-component cyclocondensation of barbituric acids $12 \mathbf{a}(\mathrm{R}=\mathrm{H})$ or $12 \mathrm{c}(\mathrm{R}=$
$\mathrm{Me}$ ), benzaldehyde (27) and nitriles 39 proceeds in the absence or presence of triethylamine to afford pyrano[2,3- $d$ ]pyrimidines 40 [83].

Bicyclic compounds of type $40(\mathrm{R}=\mathrm{H}, \mathrm{X}=$ $\mathrm{CN}$ ) have been synthesized by ultrasound (US) promoted three-component reaction between aromatic aldehydes 27, barbituric acid (12a), and malononitrile (39a) [84]. The reaction was performed in an aqueous medium without the use of a catalyst, and the products 40 were obtained in good yields.

Also, biologically active pyrano[2,3- $d]$ pyrimidine derivatives (40, $\mathrm{R}=\mathrm{H}, \mathrm{X}=\mathrm{CN})$ were efficiently synthesized in excellent yields by a three-component, onepot condensation reaction of malononitrile (39a), aromatic aldehydes 27 and barbituric acid (12a) using $\mathrm{Zn}[(\mathrm{L})$ proline] $[85,86]$ or tetrabutylammonium bromide (TBAB) [87] or in the presence of $N$-methylmorpholine [88] as a catalyst. 


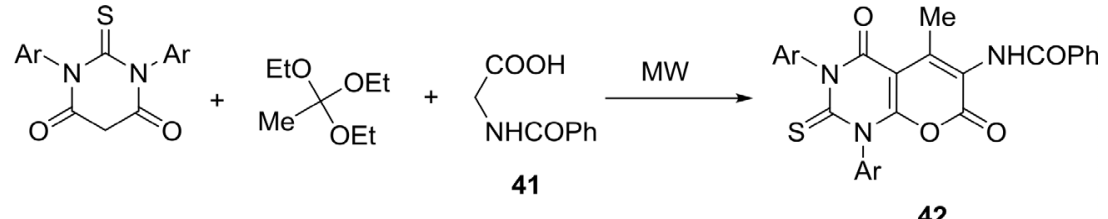

The cyclocondensation of $N, N^{\prime}$-diaryl-2-thiobarbituric acids with hippuric acid (41) and triethyl orthoacetate on basic alumina was carried out under MWI to give pyranopyrimidines $\mathbf{4 2}$ in $92-95 \%$ yields within one minute. More than five hours were required under conventional heating at $110-120{ }^{\circ} \mathrm{C}$ to afford $60-70 \%$ yields [89].

Cycloaddition of barbituric acids 12a $(\mathrm{R}=\mathrm{H})$, c $(\mathrm{R}=\mathrm{Me})$, triethyl orthoformate, and nitriles 39 in the presence of acetic anhydride under MWI for five minutes afforded pyrano[2,3- $d$ ]pyrimidines $\mathbf{4 3}$ in excellent yields [90].<smiles>[X]c1cc2c(=O)n([R])c(=O)n([R])c2oc1=N</smiles>

43

The synthesis of chromeno[2,3- $d$ ]pyrimidinones 46 and diazabenzo[b]fluorenones 47 has been devel- oped by one-pot three-component cyclocondensation of $N, N^{\prime}$-dimethylbarbituric acid (12c), aldehydes 27, and dimedone (44) or indane-1,3-dione (45) in the presence of $\mathrm{InCl}_{3}$ or $\mathrm{P}_{2} \mathrm{O}_{5}$ under solvent-free conditions [91].

Indium(III) chloride-catalyzed one-pot syntheses of 12-aryl-8,10-dimethyl-8,12-dihydro-7-oxa-8,10-diazabenzo[ $a]$ anthracene-9,11-dione derivatives 49 have been achieved by three-component cyclocondensation of $N, N^{\prime}$-dimethylbarbituric acid (12c), aldehydes 27, and $\beta$-naphthol (48) under solvent-free condition in high yields. $\mathrm{P}_{2} \mathrm{O}_{5}$ too has been found to be an effective catalyst towards this transformation [92].

Shaker et al. [93] reported that the three-component condensation of indan-1,2,3-triones (50), malononitrile (39a) and barbituric acids 12a $(\mathrm{R}=\mathrm{H}, \mathrm{X}=\mathrm{O})$, b $(\mathrm{R}=\mathrm{H}, \mathrm{X}=\mathrm{S})$ as well as $N, N^{\prime}$-diethyl-2-thiobarbituric acid in the presence of piperidine under microwave irradiation without solvent afford the corresponding spiro-fused pyran derivatives $\mathbf{5 1}$.<smiles>Cn1c2c(c(=O)n(C)c1=O)C([Al])C1=C(CC(C)(C)CC1=O)O2</smiles> 
<smiles>O=c1c(=O)c2ccccc2c1=O</smiles>

50<smiles></smiles>

51<smiles>[R]N1C(=O)C(=O)c2ccccc21</smiles>

52<smiles></smiles>

53
$\underbrace{}_{\mathrm{O}}+\mathrm{Ar}-\mathrm{CHO}+\mathrm{H}_{2}{ }_{\mathrm{NH}_{2}}^{\mathrm{N}}$ 27

$12 \mathrm{a}$
A simple and efficient one-pot three-component synthesis of the biologically important spirooxindoles 53 was carried out by the reaction of isatins $\mathbf{5 2}$, nitriles 39, and barbituric acids $\mathbf{1 2}$ in aqueous medium. A Knoevenagel condensation occurred first between isatin and the malonitrile derivative, followed by Michael addition of barbituric acids and cyclization via the cyano moiety $[94,95]$.

\section{Biginelli heterocyclic synthesis}

The Biginelli reaction, discovered by Pietro Biginelli in 1893, is a multicomponent reaction allowing the synthesis of DHPMs by reacting urea, a dicarbonyl derivative, and an aldehydic component. An increased interest in this process has been shown during the past few years; recent investigations aimed at performing the MCR under milder conditions, increasing the yields and opening the scope of the different partners. An abundant literature covers all these aspects including a recent compilation of catalytic systems [96].

4 - Aryl - 3, 4 - dihydropyrimido [4, 5 - d] pyrimidine 2(1H)-one $\mathbf{5 4}$ has been synthesized under solvent-free microwave conditions using three component condensations of aldehydes $\mathbf{2 7}$, urea or thiourea and barbituric acid (12a) [97-99].

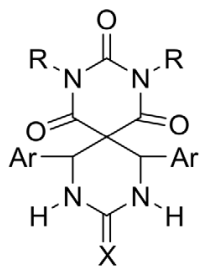

$55, X=O, S, N H$
The one-pot reaction of a mixture of barbituric acids 12a $(\mathrm{R}=\mathrm{H}), \mathbf{c}(\mathrm{R}=\mathrm{Me})$, aldehydes 27 and urea or thiourea gave the 2,4,8,10-tetraazaspiro[5.5]undecane-1,3,5-trione (55). The reaction can be promoted either in acetic acid as solvent or neat under microwave irradiation or in the presence of $\mathrm{H}_{3} \mathrm{PW}_{12} \mathrm{O}_{40}$ or iodine as catalysts [100-104].

\section{Hantzsch heterocyclic synthesis}

1,4-Dihydropyridines (1,4-DHPs) and their derivatives are important classes of bioactive molecules in the pharmaceutical field [105] and constitute also interesting biomimetic reducing agents $[106,107]$. Over the years, the great biological importance of these various symmetric or unsymmetrical 1,4-DHPs has prompted the development of new improved methodologies for their synthesis. According to the original procedure described by Hantzsch in 1882, the reaction is conducted either in acetic acid or in refluxing alcohols for long reaction times, but these rather harsh conditions typically lead to low yields. Aiming at developing more efficient and environmentally benign Hantzsch reactions, some procedures involving different activating modes such as microwave irradiations [108, 109], ultrasonic irradiations $[110,111]$, or even use of solar energy as a free energy source [112] have been reported. Conventional organic solvents have also been replaced by water [113] or reusable fluoroalcohols [114]. One example of the synthesis of polyhydroquinolines was also described under solvent-free conditions on grinding [115]. Alternatively, task-specific ionic liquids were used as soluble support on which the $\beta$-ketoesters were bound [116]. 
<smiles>[R16]C1CC(=O)N([R])C(=[X])N1[R]</smiles><smiles>O=C1CC(=O)NC(=O)N1</smiles><smiles>CC(C)C(C)C(=O)[OH+]</smiles><smiles>Cc1cc(N)n(-c2ccccc2)n1</smiles>

The tetrahydropyrimido[4,5- $b$ ]quinolines $\mathbf{5 7}$ have been synthesized in high yields using ultrasound irradiation in an efficient one-pot, three-component process by a condensation reaction of barbituric and thiobarbituric acids 12a-c, aldehydes 27 and 3-amino-5,5-dimethylcyclohex-2-enone (56) in water [117].

A series of 7-aryl-11,12-dihydrobenzo[ $h]$ pyrimido[4,5-b]quinoline-8,10(7H,9H)-diones 59 were synthesized via three-component reaction of aldehydes 27, $\alpha$-naphthylamine (58) and barbituric acid (12a) in an ionic liquid [118].

Similarly, the three-component reaction of aldehydes 27, $\beta$-naphthylamine (60) and barbituric acid (12a) at r.t. yield the benzo[ $f]$ pyrimido[4,5- $b$ ]quinoline-9,11-dione 61 in excellent yields [119-121].

The first results in the synthesis of pyrazolopyridopyrimidines by MCR of aminopyrazole 62, aldehydes 27, and barbituric acid (12a) were published in 2008 by Shi et al. [122]. They used "green chemistry" methodology and carried out treatment of the starting materials in water under microwave irradiation. The temperature optimization procedure and the search for the best catalytic system allowed selecting one equiv- alent of $p$-TSA and $140{ }^{\circ} \mathrm{C}$ as optimum conditions for the synthesis. With application of the elaborated procedure, 24 novel pyrazolopyridopyrimidines 63 were generated.

A detailed study of the MCRs involving barbituric acids $12 \mathbf{a}-\mathbf{d}(\mathrm{R}=\mathrm{H}, \mathrm{Me} ; \mathrm{X}=\mathrm{O}, \mathrm{S})$ and 5-aminopyrazoles was published by Muravyova et al. [123]. The article describes the development of chemoselective cyclocondensations with the help of microwave and ultrasonic irradiation. It was established that the temperature was the main factor in controlling the direction of the MCRs studied. At high temperatures $\left(170-190{ }^{\circ} \mathrm{C}\right)$ the starting materials reacted in two different ways. It was found that a substituent in the position 1 of aminopyrazoles strongly influences the nature of the reaction products. In the case of $N$-substituted aminopyrazoles (both with electronwithdrawing and with electron-releasing $\mathrm{R}^{1}$ groups), the reaction yielded pyrazolopyrido-pyrimidines $\mathbf{6 6}$. When $\mathrm{R}^{1}=\mathrm{H}$, MCRs at high temperature in DMF always gave dihydro derivatives $\mathbf{6 7}$. Interesting results also concern the microwave-assisted treatment. Application of controlled MW irradiation (temperatures 

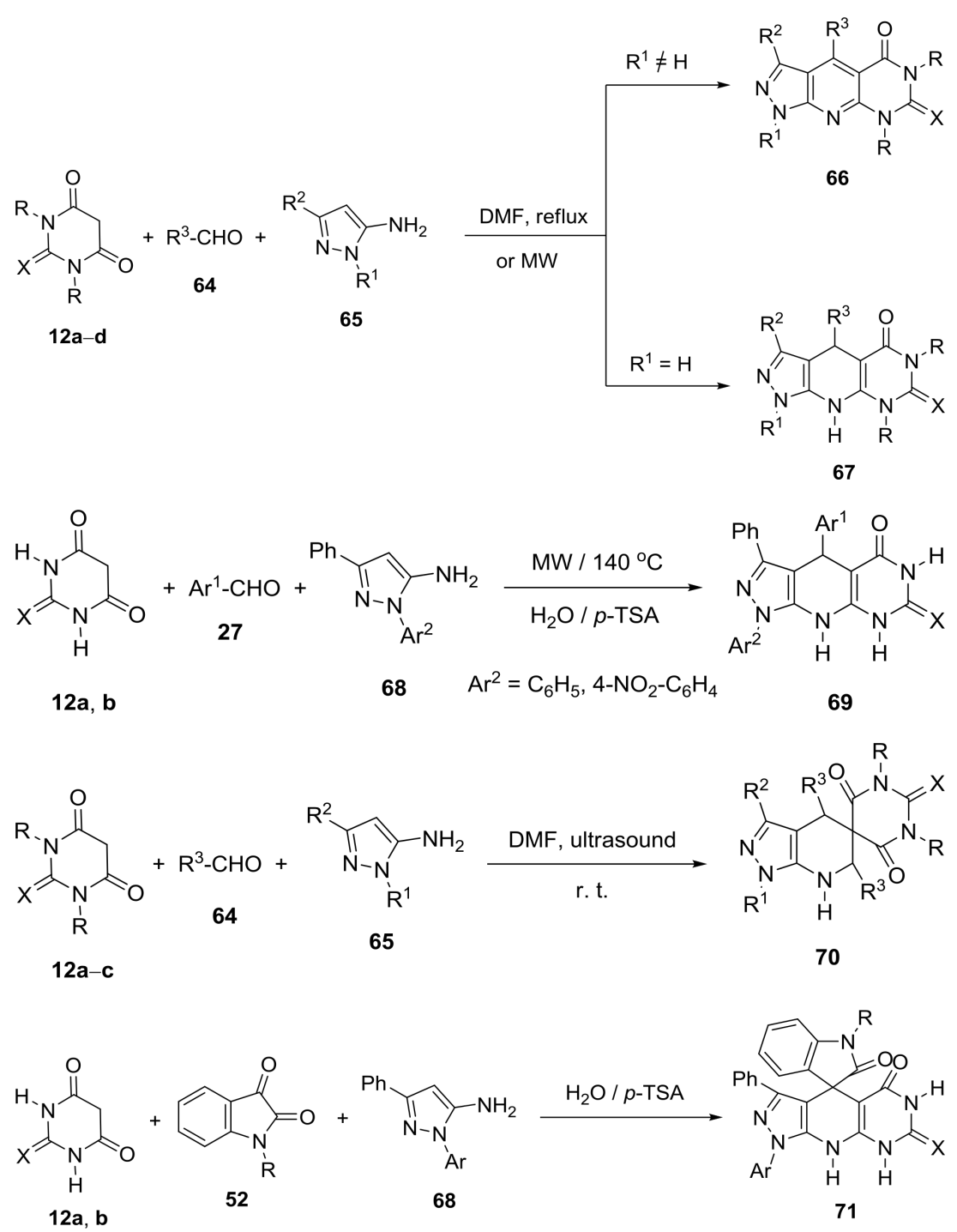

from 150 to $190^{\circ} \mathrm{C}$ ) when carrying out MCRs involving $N$-unsubstituted pyrazoles did not give any positive result and led to complicated mixtures of several inseparable products. However, using a microwave field to promote the reaction when $\mathrm{R}^{1} \neq \mathrm{H}$ was successful. The most preferable microwave-assisted procedure for the synthesis of compound $\mathbf{6 7}$ from the viewpoint of the yields and purity consisted in the treatment of the starting building blocks in DMF under microwave irradiation at $190{ }^{\circ} \mathrm{C}$ for $3 \mathrm{~min}$.

It has been found that a mixture of $1 \mathrm{H}$-pyrazol5-amines 68, aldehydes 27, and barbituric acids 12a $(\mathrm{X}=\mathrm{O}), \mathbf{b}(\mathrm{X}=\mathrm{S})$ in the presence of a catalytic amount of $p$-toluenesulfonic acid ( $p$-TSA) at $100{ }^{\circ} \mathrm{C}$ under solvent-free condition afforded pyrazolo $\left[4^{\prime}, 3^{\prime}: 5,6\right]$ pyrido $[2,3-d]$ pyrimidinedione derivatives $69[117,124]$. Most of the compounds exhibited good to excellent antibacterial activity against all the tested strains [124].

On the other hand, unexpectedly it was additionally established that the MCR of barbituric acids $\mathbf{1 2 a}$, b $(\mathrm{R}=\mathrm{H} ; \mathrm{X}=\mathrm{O}, \mathrm{S}), \mathbf{c}(\mathrm{R}=\mathrm{Me} ; \mathrm{X}=\mathrm{O})$, aldehydes 64 and aminopyrazole $\mathbf{6 5}$ at r.t. under ultrasonication or with the help of simple stirring yielded a novel type of spirocompounds 70 [123].

A water-based "green" protocol under conventional heating was used to carry out three-component reactions of 3-substituted 5-aminopyrazoles $\mathbf{6 8}$, bar- 
<smiles>[R]c1c([R])c([R])c2c([R])c3c(=O)[nH]c(=O)[nH]c3nc2c1[R]</smiles><smiles></smiles>

74

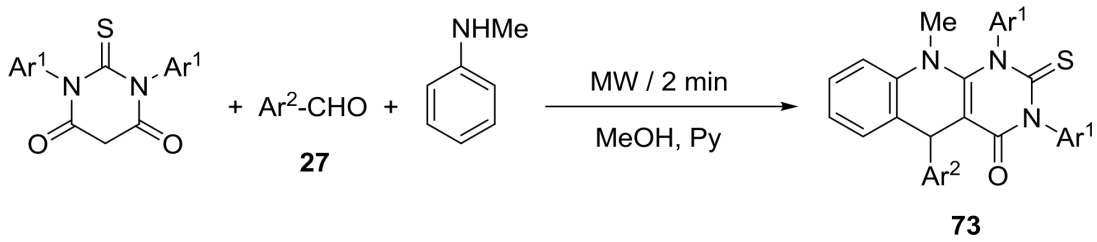<smiles></smiles>

$12 a, b$<smiles>Nc1c[nH]c(=O)n([IH+])c1=O</smiles>

75<smiles></smiles>

76<smiles></smiles>

bituric acids 12a $(X=O), \mathbf{b}(X=S)$ and isatin 52 derivatives. The reaction produced the required spiroheterocycles $\mathbf{7 1}$ in excellent yields and purity $[125,126]$.

Functionalized pyrimido[4,5- $b$ ]quinoline-2,4(1H, $3 H$ )-diones $\mathbf{7 2}$ were synthesized by a three-component one-pot reaction involving anilines, barbituric acid (12a), and either formaldehyde, an aliphatic, or an aromatic aldehyde [127].

A one-pot synthesis of pyrimido[4,5-b]quinolines 73 under MWI involved the reaction of $N, N^{\prime}$-diaryl-2-thiobarbituric acids, the appropriate aldehydes 27, and $N$-methylaniline to give $72-88 \%$ yield after $2 \mathrm{~min}$, compared to $1.5-2 \mathrm{~h}$ under conventional thermal conditions [128].

The three-component condensation of barbituric and thiobarbituric acids $\mathbf{1 2}$ with aldehydes 27 and ammonia or anilines provides derivatives of pyrido[2,3- $\left.d: 6,5-\mathrm{d}^{\prime}\right]$ dipyrimidine 74 [129, 130].
Shaker et al. [131] have described the synthesis of pyrido[3,2-d:6,5-d']dipyrimidine derivatives $\mathbf{7 6}$ through a one-pot reaction of 5-aminouracil (75), aldehydes 27 and barbituric acids 12a, b under microwave irradiation.

The three-component one-pot cyclocondensation reaction of barbituric acids $\mathbf{1 2 a}-\mathbf{c}$, aldehydes 27 and 6-aminouracils $\mathbf{7 7}$ for the synthesis of pyrido[2,3$d: 6,5-d^{\prime}$ ]dipyrimidines $\mathbf{7 8}$ in refluxing water has been reported [132]. Most of the compounds have a narrow to good spectrum of antimicrobial activity [132].

\section{Summary}

Literature data published in the last 47 years have been summarized to help the reader to find information appropriate for the use of multi-component reactions of barbituric acid derivatives in the synthesis of heterocyclic compounds with pharmacological interest.
[1] J. G. Hardman, L. E. Limbird, A. G. Gilman, (Eds.), Goodman \& Gilman's The Pharmacological Basis of Therapeutics, $10^{\text {th }}$ ed., McGraw-Hill, New York, 2001, pp. $343-344,412-419,473,531-533$.

[2] D. A. Williams, T. L. Lemke (Eds.), Foye's Principles of Medicinal Chemistry, $5^{\text {th }}$ ed., Lippincott Williams \& Wilkins, Baltimore, 2002, pp. 367.

[3] G. L. Patrick, An Introduction to Medicinal Chemistry, $3^{\text {rd }}$ ed., Oxford University Press, Oxford, 2005, pp. 579.
[4] L. L. Brunton, J. S. Lazo, K. L. Parker (Eds.), Goodman \& Gilman's The Pharmacological Basis of Therapeutics, $11^{\text {th }}$ ed., McGraw-Hill, New York, 2006.

[5] S. H. Kim, A. T. Pudzianowski, K. J. Leavitt, Bioorg. Med. Chem. Lett. 2005, 15, 1101.

[6] A. R. Daniewski, W. Liu, M. Okabe, Org. Proc. Res. Dev. 2004, 8, 411.

[7] H. Suzuki, M. B. Kneller, D. A. Rock, J. P. Jones, Arch. Biochem. Biophys. 2004, 429, 1. 
[8] M. K. Haldar, M. D. Scott, N. Sule, Bioorg. Med. Chem. Lett. 2008, 18, 2373.

[9] D. J. Cordato, G. K. Herkes, L. E. Mather, J. Clin. Neurosci. 2003, 10, 283.

[10] Y. Furukawa, European Patent Appl EP 88, 413, 1983; Chem. Abstr. 1983, 100, 22688.

[11] S. Budavari, The Merck Index, $11^{\text {th }}$ ed., Merck, Rahway 1989.

[12] S. L. Katz, A. W. Gay, US Patent 352 806, 1982; Chem. Abstr. 1983, 98, 215603.

[13] W. G. Brouwer, E. E. Felauerand, A. R. Bell, US Patent 779982990 1990; Chem. Abstr. 1991, 114, 185539.

[14] C. L. Kliethermes, P. Metten, J. K. Belknap, Brain Res. 2004, 1009, 17.

[15] S. Senda, H. Fugimura, H. Izumi, Japan Patent 193,6824, 1968; Chem. Abstr. 1969, 70, 78001.

[16] L. K. Akopyan, A. S. Adzhibekyan, G. A. Porkinyan, E. A. Tumasyan, Bilzh. Arm. 1976, 29, 80; Chem. Abstr. 1976, $85,72068$.

[17] N. Svenstrup, A. Kuhl, K. Ehlert, D. Häbich, Bioorg. Med. Chem. Lett. 2008, 18, 3215.

[18] Q. Yan, R. Cao, W. Yi, Z. Chen, H. Wen, L. Ma, H. Song, Eur. J. Med. Chem. 2009, 44, 4235.

[19] T. Tomašić, N. Zidar, M. Mueller-Premru, D. Kikelj, L. P. Mašič, Eur. J. Med. Chem. 2010, 45, 1667.

[20] P. Prisyazhnik, G. Palii, Y. Volydnskii, A. Lopushanskii, E. Opanasenko, Khim. Farm. Zh. 1976, 10, 46.

[21] M. Omar, Egypt J. Pharm. Sci. 1998, 38, 281.

[22] C. Uhlmann, W. Froscher, CNS Neurosci. Ther. 2009 , $15,24$.

[23] S. Archana, V. K. Srivastava, A. Kumar, Bioorg. Med. Chem. 2004, 12, 1257.

[24] A. Agarwal, S. Lata, K. K. Saxena, V. K. Srivastava, A. Kumar, Eur. J. Med. Chem. 2006, 41, 1223.

[25] E. Maquoi, N.E. Sounni, L. Devy, F. Oliver, F. Frankenne, H. W. Krell, F. Grams, J. M. Foidart, A. Noel, Clin. Cancer Res. 2004, 10, 4038.

[26] B.S. Jursic, F. Doulle, E. D. Stevens, Tetrahedron 2003, 59, 3427.

[27] N.R. Penthala, T.R. Yerramreddy, P.A. Crooks, Bioorg. Med. Chem. Lett. 2011, 21, 1411.

[28] C. Uhlmann, W. Froscher, CNS Neurosci. Ther. 2009, 15, 24.

[29] P. Singh, M. Kaur, P. Verma, Bioorg. Med. Chem. Lett. 2009, 19, 3054.

[30] L. R. Morgan, B. S. Jursic, C. L. Hooper, D. M. Neumann, K. Thangaraj, B. LeBlanc, Biorg. Med. Chem. Lett. 2002, 12, 3407.

[31] W. G. Brouwer, E. E. Felauerand, A. R. Bell, US Patent 779,982, 1990. Chem. Abstr. 1991, 114, 185539.

[32] A. Esanu, BE Patent 902,232, 1985; Chem. Abstr. 1986, 104, 130223.

[33] A. Padmaja, T. Payani, G. D Reddy, V. Padmavathi, Eur. J. Med. Chem. 2009, 44, 4557.
[34] J. S. Biradar, B. S. Sasidhar, R. Parveen, Eur. J. Med. Chem. 2010, 45, 4074.

[35] S. Rajamaki, A. Innitzer, C. Falciani, C. Tintori, F. Christ, M. Witvrouw, Z. Debyser, S. Massa, M. Botta, Bioorg. Med. Chem. Lett. 2009, 19, 3615.

[36] L. Ji, F.-E. Chen, B. Xie, E. De Clercq, J. Balzarini, C. Pannecouque, Eur. J. Med. Chem. 2007, 42, 198.

[37] J.L. Fillaut, I. De Los Rios, D. Masi, A. Romerosa, F. Zanobini, M. Peruzzini, Eur. J. Inorg. Chem. 2002, 935.

[38] O. Temiz-Arpaci, A. Ozdemir, I. Yalcin, I. Yildiz, E. Aki-Sener, N. Altanlar, Arch. Pharm. Chem. Life Sci. 2005, 338, 105.

[39] J. N. Delgado, W. A. Remers, (Eds.), Wilson and Gisvold's Textbook of Organic Medicinal and Pharmaceutical Chemistry, $9^{\text {th }}$ ed., Lippincott, Philadephia, 1991, pp. 39, 341, 376.

[40] M. W. Johns, Drugs 1975, 9, 448.

[41] M. Kawaguchi, H. Furuya, P. M. Patel, J. Anesth. 2005, 19,150

[42] C. E. Schneemilch, T. Hachenberg, S. Ansorge, A. Ittenson, U. Bank, Eur. J. Anaesthesiol. 2005, 22, 616.

[43] J. G. Hardman, L.E. Limbird, P. B. Molinoff, R. W. Ruddon, A. G. Gilman (Eds.), Goodman \& Gilman's The Pharmacological Basis of Therapeutics, $9^{\text {th }}$ ed., McGraw-Hill, New York, 1996, p. 471.

[44] Archana, V. K. Srivastava, A. Kumar, Arzneim. Forsch./Drug Res. 2002, 52, 787.

[45] W. Fraser, C. J. Suckling, H. C. S. Wood, J. Chem. Soc., Perkin Trans. 1 1990, 3137.

[46] A. N. Osman, M. M. Kandeel, M. Ahmed, Indian J. Chem. 1996, 35B, 1073.

[47] Archana, P. Rani, K. Bajaj, V. K. Srivastava, R. Chandra, A. Kumar, Arzneim.-Forsch./Drug Res. 2003, 53, 301.

[48] G. V. S. R. Sarma, J. V. Rao, B. Suresh, Indian J. Pharm. Sci. 1999, 61, 105.

[49] W. O. Foye, T. L. Lemke, D. A. Williams, Principles of Medicinal Chemistry, $4^{\text {th }}$ ed. Lippincott Williams \& Wilkins, Baltimore, 1995, pp. 88, 89, 154-180.

[50] L. Lomlin, J. Einsiedel, F. W. Heinemann, K. Meyer, P. Gmeiner, J. Org. Chem. 2008, 73, 3608.

[51] P. Singh, K. Paul, J. Heterocycl. Chem. 2006, 43, 607.

[52] E. M. Galati, M. T. Monforte, N. Miceli, E. Raneri, Farmaco 2001, 56, 459.

[53] R. J. Prankerd, R. H. McKeown, Int. J. Pharm. 1992, 83, 39.

[54] J. L. Mokrosz, Pharmazie 1985, 40, 359.

[55] A. Padwa, Chem. Soc. Rev. 2009, 38, 3072.

[56] D. M. D’Souza, T. J. J. Müller, Chem. Soc. Rev. 2007, 36, 1095.

[57] A. Domling, Chem. Rev. 2006, 106, 17.

[58] C. J. Li, Chem. Rev. 2005, 105, 3095.

[59] J. M. M. Verkade, L. J. C. Van Hemert, P. J. L. M. 
Quaedflieg, F. P. J. T. Rutjes, Chem. Soc. Rev. 2008, 37, 29.

[60] M. Arend, B. Westermanm, N. Risch, Angew. Chem. 1998, 110, 1096; Angew. Chem. Int. Ed. 1998, 37, 1045

[61] V. Singh, R. Khanna, V. K. Srivastava, G. Palit, K. Shanker, Arzneim.-Forsch. 1992, 42, 277.

[62] L. Rylski, L. Senczuk, K. Falandysz, L. Konopka, D. Zimna, Acta Pol. Pharm. 1967, 24, 369.

[63] J. A. Vida, M. L. Hooker, J. Med. Chem. 1973, 16, 602.

[64] H. J. Roth, R. Brandes, Arch. Pharm. (Weinheim, Ger.) 1966, 299, 612.

[65] H. J. Roth, K. Jager, R. Brandes, Arch. Pharm. (Weinheim, Ger.) 1965, 298, 885.

[66] B. Danielsson, J. Dolby, Acta Pharm. Suec. 1964, 1, 91.

[67] W. Werner, H. Fritzsche, Arch. Pharm. (Weinheim, Ger.) 1969, 302, 188.

[68] H. Sladowska, Farmaco, Ed. Sci. 1977, 32, 866.

[69] H. J. Roth, B. Mühlenbruch, Arch. Pharm. (Weinheim, Ger.) 1970, 303, 156.

[70] P. Kumar, C. Nath, J.C. Agarwal, K. P. Bhargava, K. Shanker, Indian J. Chem., Sect. B 1983, 22, 955.

[71] A. Kumar, S. Singh, A. K. Saxena, K. Shanker, Indian J. Chem., Sect. B 1988, 27, 443.

[72] A. Singh, V.S. Misra, Pharmacol. Res. 1989, 21, 59; Chem. Abstr. 1989, 111, 49906z.

[73] M. Kidwai, R. Thakur, R. Mohan, Acta Chim. Slov. 2005, 52, 88.

[74] D. Vulpes, M. Hrubaru, R. Nutiu, Rev. Chim. (Bucuresti) 2009, 60, 596.

[75] A. Kumar, R. A. Maurya, Tetrahedron Lett. 2008, 49, 5471.

[76] L. F. Tietze, J. Heterocycl. Chem. 1990, 27, 47.

[77] L. L. Gozalishvili, T. V. Beryozkina, I. V. Omelchenko, R. I. Zubatyuk, O. V. Shishkin, N. N. Kolos, Tetrahedron 2008, 64, 8759.

[78] A. Shaabani, M. B. Teimouri, H. R. Bijanzadeh, Tetrahedron Lett. 2002, 43, 9151.

[79] M. B. Teimouri, R. Bazhrang, Bioorg. Med. Chem. Lett. 2006, 16, 3697.

[80] I. Yavari, M. Anary-Abbasinejad, A. Alizadeh, Monatsh Chem. 2002, 133, 1221.

[81] I. Yavari, N. Hazeri, M. T. Maghsoodlou, N. ZabarjadShiraz, Monatsh Chem. 2001, 132, 683.

[82] I. Yavari, M. T. Maghsoodlou, J. Chem. Res. (S) 1998, 386.

[83] I. Devi, B. S. D. Kumar, P. J. Bhuyan, Tetrahedron Lett. 2003, 44, 8307.

[84] T.-S. Jin, L.-B. Liu, Y. Zhao, T.-S. Li, J. Chem. Res. 2005, 162.

[85] M. M. Heravi, A. Ghods, K. Bakhtiari, F. Derikvand, Synthetic Commun. 2010, 40, 1927.

[86] M. Bararjanian, S. Balalaie, B. Movassagh, A. M. Amani, J. Iran. Chem. Soc. 2009, 6, 436.
[87] A. Mobinikhaledi, M. A. B. Fard, Acta Chim. Slov. 2010, 57, 931.

[88] A. A. Shestopalov, L. A. Rodinovskaya, A. M. Shestopalov, V. P. Litvinov, Russ. Chem. Bull., Int. Ed. 2004, 53, 2342.

[89] M. Kidwai, R. Venkataramanan, R. K. Garg, K. R. Bhushan, J. Chem. Res (S) 2000, 586.

[90] I. Devi, P. Bhuyan, Synlett 2004, 283.

[91] R. Kumar, K. Raghuvanshi, R. K. Verma, M. S. Singh, Tetrahedron Lett 2010, 51, 5933.

[92] G. C. Nandi, S. Samai, R. Kumar, M. S. Singh, Tetrahedron 2009, 65, 7129.

[93] R. M. Shaker, A.F. Mahmoud, F.F. Abdel-Latif J. Chin. Chem. Soc. 2005, 52, 563.

[94] S. L. Zhu, S. J. Ji, Y. Zhang, Tetrahedron 2007, 63, 9365.

[95] M. N. Elinson, A. I. Ilovaisky, V. M. Merkulova, D. V. Demchuk, P. A. Belyakov, Y. N. Ogibin, G. I. Nikishin, Electrochim. Acta 2008, 53, 8346.

[96] M. A. Kolosov, V. D. Orlov, D. A. Beloborodov, V. V. Dotsenko, Mol Divers 2009, 13, 5.

[97] S. V. Shinde, W. N. Jadhav, N. N. Karde, R.H. Tale, A. Chaudhari, Bull. Cat. Soc. India 2009, 8, 157.

[98] M. Kidwai, K. Singhal, S. Kukreja, Z. Naturforsch. 2007, 62b, 732 .

[99] A. H. Kategaonkar, S. A. Sadaphal, K. F. Shelke, B. B. Shingate, M. S. Shingare, Ukrainica Bioorganica Acta 2009, 1,3 .

[100] M. M. Amini, A. Shaabani, A. Bazgir, Catal. Commun. 2006, 7, 843.

[101] M. M. Abelman, S. C. Smith, D. R. James, Tetrahedron Lett. 2003, 44, 4559.

[102] A. Shaabani, A. Bazgir, Tetrahedron Lett. 2004, 45, 2575.

[103] G. Byk, E. Kabha, Synlett 2006, 747.

[104] D. Prajapati, D. Bhuyan, M. Gohain, W. Hu, Mol Divers 2011, 15, 257.

[105] G. M. Reddy, M. Shiradkar, A. K. Chakravarthy, Curr. Org. Chem. 2007, 11, 847.

[106] Y. Murakami, J. Kikuchi, Y. Hisaeda, O. Hayashida, Chem Rev. 1996, 96, 721.

[107] Y. Sambongi, H. Nitta, K. Ichihashi, M. Futai, I. Ueda, J. Org. Chem. 2002, 67, 3499.

[108] A. Mobinikhaledi, N. Foroughifar, M. A. B. Fard, H. Moghanian, S. Ebrahimi, M. Kalhor, Synth Commun. 2009, 39, 1166.

[109] S. B. Sapkal, K. F. Shelke, B. B. Shingate, M. S. Shingare, Tetrahedron Lett. 2009, 50, 1754.

[110] A. Kumar, R. A. Maurya, Synlett 2008, 883.

[111] S.X. Wang, Z. Y. Li, J.C. Zhang, J.T. Li, Ultrason Sonochem 2008, 15, 677.

[112] R. A. Mekheimer, A. A. Hameed, K. U. Sadek, Green Chem. 2008, 10, 592. 
[113] B. P. Bandgar, P.E. More, V. T. Kamble, J. V. Totre, Arkivoc 2008, xv, 1 .

[114] A. Heydari, S. Khaksar, M. Tajbakhsh, H. R. Bijanzadeh, J. Fluor. Chem. 2009, 130, 609.

[115] S. Kumar, P. Sharma, K. K. Kapoor, M.S. Hundal, Tetrahedron 2008, 64, 536.

[116] J. C. Legeay, J. Y. Goujon, J. J. V. Eynde, L. Toupet, J. P. Bazureau, J. Comb. Chem. 2006, 8, 829.

[117] M. H. Mosslemin, M. R. Nateghi, Ultrasonics Sonochemistry 2010, 17, 162.

[118] H. Y. Guo, Y. Yu, Chinese Chem. Lett. 2010, 21, 1435.

[119] N. G. Kozlov, L. I. Basalaeva, Russ. J. Org. Chem. 2007, 43, 432.

[120] X. S. Wang, Q. Li, J.R. Wu, M. M. Zhang, Chinese J. Struct. Chem. 2010, 29, 335.

[121] N. G. Kozlov, S. L. Bondarev, B. A. Odnoburtsev, L. I. Basalaeva, Russ. J. Appl. Chem. 2007, 80, 1101.

[122] F. Shi, D. Zhou, S. Tu, C. Li, L. Cao, Q. Shao, J. Heterocycl. Chem. 2008, 45, 1305.

[123] E. A. Muravyova, S. V. Shishkina, V. I. Musatov,
I. V. Knyazeva, O. V. Shishkin, S. M. Desenko, V. A. Chebanov, Synthesis 2009, 1375.

[124] A. Bazgira, M. M. Khanaposhtani, A. A. Soorki, Bioorg. Med. Chem. Lett. 2008, 18, 5800.

[125] R. Ghahremanzadeh, M. Sayyafi, S. Ahadi, A. Bazgir, J. Comb. Chem. 2009, 11, 393.

[126] J. Quiroga, S. Portillo, A. Pérez, J. Gálvez, R. Abonia, B. Insuasty, Tetrahedron Lett. 2011, 52, 2664.

[127] K. Aknin, S. Desbène-Finck, P. Helissey, S. GiorgiRenault, Mol Divers 2010, 14, 123.

[128] V. K. Ahluwalia, B. Goyal, U. Das, J. Chem. Res. (S) 1997, 266.

[129] V. K. Ahluwalia, U. Das, R. Kumar, Indian J. Chem., Sect. B 1996, 35, 852.

[130] R. K. Khajuria, S. R. Sharma, S. M. Jain, S. Sharma, A. Kapil, Indian J. Chem., Sect., B 1993, 32, 981.

[131] R. M. Shaker, M. A. Ameen, A. M. Abdel Hameed, M. Abd Elrady, Z. Naturforsch. 2009, 64b, 1193.

[132] A. Bazgir, M. M. Khanaposhtani, R. Ghahremanzadeh, A. A. Soorki, Comptes Rendus Chimie 2009, 12, 1287. 